\title{
The Separation of Agricultural Household-Evidence from China
}

\author{
Chen LU ${ }^{1}$, Yuyu WANG \\ ${ }^{1}$ Tan Kah Kee College, Xiamen University, Fujian Province, China, 363105 \\ ${ }^{2}$ Graduate School of Economics, Nagoya University, Nagoya, Japan, 464-8601 \\ luchen@xujc.com, wang.yuyu@c.mbox.nagoya-u.ac.jp
}

\begin{abstract}
By using the CHIPS (2002) data, this paper applies the empirical model developed by Benjamin (1992) to test the separation of households' consumption and labor supply considerations. Our empirical results show that only the household with medium size of land in east China cannot be excluded from the null hypothesis of reparability, which indicates the prevailing feature of non-separation of agricultural households in China.

Index Terms - Agricultural household models, rural labor market, labor demand, separability
\end{abstract}

\section{Introduction}

The farm production in in developing countries is carried out by households that both demand and supply labor. If these households are able to exchange land and labor freely through reasonably competitive factor markets, then the amount of labor used in production would in theory be independent of their consumption and labor supply considerations. As pointed by Benjamin (1992), whether agricultural households are price-taking participants in a clearing labor market plays the central role in developing economics.

Separability is a relevant issue for China because of the development of rural labor markets and employment. Before 1978, rural employment in China was predominantly in agricultural and self-employment was almost non-existing and household business as a demand factor in rural labor markets was negligible (Wang, et al., 2007). Despite substantial economic reforms in rural China since 1990s, rural households still face restrictions in their labor allocation and the development of factor markets has lagged.

Many scholars have empirically analyzed the separation of agricultural household models. By using the data from Malaysia, Benjamin (1992) concludes that there is no influence of family structure on the labor demand of farm in Malaysia. Based on Benjamin (1992), Bowlus and Sicular (2003) tested for the separability by using panel data covering from a survey of Chinese farm households. Their empirical results find that labor demand is a function of household size and composition and rejected the hypothesis that labor demand and supply are separable. Their research indicates that despite considerable progress in market reforms, in the early 1990s rural households in China apparently still faced difficulties transferring labor and land optimally in response to changes in household size and composition. Recent research conducted by Wang et al. (2007) used micro-level data from Zhejiang province over the period 1995-2002 and their research concludes that the decisions to hire labor and participation off the farm are made jointly and are positively correlated. Their research also suggests that non-separability between hired labor demand and household characteristics, indicating the rural labor market in the province concerned is still functioning imperfectly.

Our paper is an extension of Bowlus and Sicular (2003) in two aspects. Firstly, we use China Household Income Projects (CHIPS) data for empirical analysis. The data set is superiors to the one used in previous research since it covers national household. Secondly, our empirical research is consistent with the one obtained by their research concerning the separability of agricultural household in the east China. However, our paper shows that the east and middle regions in China have distinct non-separability of consumption and labor supply considerations.

Our empirical results firstly show that the separation of agricultural household is closely related with economic level. More specifically, there exists the non-separability of households in the west and middle regions of China. Only those households with medium land size in east China can reject the null hypothesis. Secondly, not only economic status of agricultural households but also less development of labor market in rural area contributes to the non-separability of agricultural households.

The rest of our paper is structured as follows: in the next section, we specify the model used for our empirical analysis. The data description is presented in the third section. The following section centers on the test of the separability and the final section concludes.

\section{Model Specification}

Separability of production and consumption greatly simplifies empirical analysis of farm production behavior, and so empirical studies usually assume that separability holds. In this paper, we follow Benjamin (1992) and estimate the demand for labor in farm production as a function of household size and composition. Our empirical model is ${ }^{1}$ :

$$
\ln L_{j}=\alpha+\gamma \ln A_{j}+\delta_{0} \ln n_{j}+\sum_{i=1}^{D} \delta_{i} \frac{n_{j}^{i}}{n_{j}}+\sum_{i=1}^{K} \theta_{i} D_{i}+\sum_{i=1}^{M} \rho_{j} X_{i}+\varepsilon_{j}
$$

$j=1, \ldots \ldots, J$, where $L$ is labor demand defined as total

\footnotetext{
${ }^{1}$ Bowlus and Sicular (2003) used the similar empirical model as to estimate the demand for labor in farm production.
} 
person-days used on land activity by the household, $A$ cultivated land area, $n$ household structure variables, $D_{i}$ year and $X_{i}$ additional variables included to control for land quality and human capital, $\varepsilon_{j}$ an error term. $J$ refers to the number of households. The coefficient $\delta_{0}$ capture the response of labor demand to changes in household composition. The null hypothesis is that $\delta_{0}=\delta_{i}=0$ for all $i$. Rejection of the null hypothesis implies non-separability.

\section{Data Description}

Different from Bowlus and Sicular (2003), we in this paper use China Household Income Projects (CHIPS) data for empirical analysis. The project started from 1988 and the recent survey was conducted in year 2007. The data includes individual employment status, level of education, type of employers and other sources of income. The data used in this paper covers random sample of 4701 farm households surveyed in 2002. The wide range of dataset makes our paper distinct from Bowlus and Sicular (2003). Firstly, our sample covers most of provinces in China while their research only covers the sample in one province called Shandong Province. Secondly, our sample outnumbers that of theirs. Only 259 households were surveyed in their research but the sample used in our paper covers 4701 households.

However, caution should be applied when we use the national data. It is widely known that there is huge difference of income level across China, which makes it necessary to take the regional income level into consideration. Therefore, we divide the country into three different regions according to the clarification done by the China Statistics Bureau (See Table 1). The east region covers six provinces and the capital city Beijing. The middle region also covers seven provinces and the west region includes seven provinces and one municipality called Chongqin. Several provinces are excluded from our research due to the unavailability of data during the sample year.

TABLE 1 Area Descriptions

\begin{tabular}{|c|l|}
\hline Region & Provinces included \\
\hline East & $\begin{array}{l}\text { Beijing, Hebei, Liaoning, Shandong, Jiangsu, Zhejiang, } \\
\text { Guangdong (Shanghai city, Tianjin city, Fujian Province and } \\
\text { Hainan Province are excluded) }\end{array}$ \\
\hline Middle & $\begin{array}{l}\text { Jilin, Shanxi, Henan, Anhui, Hubei, Hunan, Jiangxi (Inner } \\
\text { Mongolia and Heilongiang provinces are excluded) }\end{array}$ \\
\hline West & $\begin{array}{l}\text { Xinjiang, Gansu, Shanxi, Sichuan, Guizhou, Yumnan, } \\
\text { Guangxi and Chongqin City (Ningxia, Qinhai and Xizhang } \\
\text { provinces are excluded) }\end{array}$ \\
\hline
\end{tabular}

Table 2 presents a summary of data definitions and some descriptive statistics. The dependent variables in the demand and supply functions are the working hours of hired labor within household and working hours of all family members in any off-farm occupation. The explanatory variables are grouped into two: household characteristics and types of lands. The household characteristics include cultivated land size, educational attainment, fraction of adult male and female. The land types are shown by the use of dummy variables.

TABLE 2 Data Descriptions

\begin{tabular}{|l|c|c|c|}
\hline & \multicolumn{3}{|c|}{ Mean (Std. Dev) } \\
\cline { 2 - 4 } & East & Middle & West \\
\hline $\begin{array}{l}\text { Y: (farm hours and employed } \\
\text { farm hours) }\end{array}$ & $\begin{array}{c}2408.01 \\
(1900.60)\end{array}$ & $\begin{array}{c}2389.22 \\
(1571.82)\end{array}$ & $\begin{array}{c}3353.33 \\
(1900.60)\end{array}$ \\
\hline Aj: log cultivated land size & $6.25(6.94)$ & $8.84(8.85)$ & $7.73(8.21)$ \\
\hline Nj: log household size & $3.37(0.12)$ & $3.95(1.07)$ & $4.41(1.40)$ \\
\hline n1/nj: children fraction & $0.17(0.18)$ & $0.24(0.19)$ & $0.25(0.20)$ \\
\hline $\begin{array}{l}\text { n2/nj: fraction of adult } \\
\text { female }\end{array}$ & $0.37(0.12)$ & $0.34(0.11)$ & $0.33(0.11)$ \\
\hline n3/nj: fraction of adult male & $0.38(0.14)$ & $0.36(0.14)$ & $0.36(0.15)$ \\
\hline $\begin{array}{l}\text { Xi: dummy variable for high } \\
\text { quality land }\end{array}$ & $0.13(0.33)$ & $0.13(0.34)$ & $0.39(0.49)$ \\
\hline $\begin{array}{l}\text { Xi: dummy variable for land } \\
\text { type-hills }\end{array}$ & $0.23(0.42)$ & $0.35(0.47)$ & $0.30(0.46)$ \\
\hline $\begin{array}{l}\text { Xi: dummy variable for land } \\
\text { type-water land }\end{array}$ & $0.66(0.39)$ & $0.53(0.42)$ & $0.50(0.38)$ \\
\hline Xi: years of education & $20.27(6.53)$ & $19.24(6.35)$ & $17.44(6.7)$ \\
\hline
\end{tabular}

Source: CHIPS survey data

Notes: 1 . Standard deviations are in parentheses.

2. Household size is the number of people resident in the same house or residential compound for 1 or more months during the calendar year.

3. Adults include individuals of age 18 to 65 . Individuals below age 18 are counted as children and above age 65 as elderly.

4. Years of education are the average education years for all family members.

5 Off-family labor includes both hired labor and labor exchanged between households without compensation.

As we can see from Table 2, households in west region have the highest number of family members, averaging at the 4.41 persons. It might look strange at the first glance considering the strict implements of one-child policy in China. One possible reason for this result might rely on the role played by the natural and geographical restrictions which makes the implement of the policy less possible in those remote and rural areas.

Compared with the provinces in east and middle regions, those in west regions have a distinct feature of higher fraction of children. Even though provinces in east China have the lowest family members, they have the highest level of education years, reaching at the 20.27 years per household. The fraction of three different types of land shown by the row 9-11 indicates the geographic feature of those three regions.

\section{Testing for Separability}

Considering the wide difference of economic development level in China, it is necessary to divide the sample provinces into different groups. According to the classification conducted by the China Statistics Bureau, we in this paper separate our analysis into three regions: east, middle and west. The household numbers in each region are 1417, 1791 and 
1493, respectively. Additionally, the research done by Bowlus and Sicular (2003) showed that the empirical result of separability is related to the land size. Following their idea, we further divide each region into three groups based on the land size: less than $1.5 \mathrm{mu}$, higher than 1.5 but less than 2.0 , and higher than 2.0 (see Table 3). The classification is useful when we correlate the separability with the economic level in each region.

TABLE 3 The Separation Test by Land Size within Each Region

\begin{tabular}{|c|c|c|c|}
\hline Region & Group1 & Group2 & Group3 \\
\hline East (1417) & F:13.08 (951) & $\mathrm{F}: 1.84 \quad(123)$ & F:6.54 (343) \\
\hline Middle (1791) & $\mathrm{F}: 21.21 \quad$ (922) & F:7.74 (232) & F:19.62 (637) \\
\hline East (1493) & $\mathrm{F}: 25.62 \quad(903)$ & F:9.03 (154) & $F: 14.18$ (436) \\
\hline
\end{tabular}

Note: Number of households are in parentheses.

As we can see from Table 3, the results show that both group 1 and group 3 reject the null hypothesis of separation. Only the group 2 with 123 household number in east region fail to reject the null hypothesis. Our result is consistent with the one obtained in Bowlus and Sicular (2003). On one hand, the consistency stems from the fact that their data is from the Zouping county in Shandong province which is included in our east region. On the other hand, our result shows that the nonseparation of household can be applied to all province included in east regions in China, which is the distinguishing feature of our research.

Since only the group 2 cannot reject the null hypothesis, we would like to conduct further analysis. The result is summarized in the Table 4.

TABLE 4 The Separation Test of Group 2

\begin{tabular}{|l|c|c|c|}
\hline & East & Middle & West \\
\hline log cultivated land size & $0.47(0.53)$ & $0.08(0.12)$ & $-0.70(-1.32)$ \\
\hline log family size & $0.54 * *(2.18)$ & $\begin{array}{c}0.77 * * * \\
(3.85)\end{array}$ & $\begin{array}{c}0.74 * * * \\
(4.96)\end{array}$ \\
\hline Children fraction & $0.52(1.01)$ & $-0.40(-0.92)$ & $0.62(1.76)$ \\
\hline fraction of adult female & $1.43^{* *}(2.18)$ & $0.15(0.27)$ & $\begin{array}{c}1.75^{* * *} \\
(3.62)\end{array}$ \\
\hline fraction of adult male & $0.68(1.24)$ & $\begin{array}{c}1.10^{* *} \\
(2.31)\end{array}$ & $\begin{array}{c}1.49 * * * \\
(3.92)\end{array}$ \\
\hline $\begin{array}{l}\text { (mountain rage) } \\
\text { dummy variable }\end{array}$ & $-0.02(-0.09)$ & $0.07(0.45)$ & $0.21(1.07)$ \\
\hline (hills) dummy variable & $0.27(1.60)$ & $-0.87(-0.07)$ & $0.17(0.91)$ \\
\hline $\begin{array}{l}\text { (water land) } \\
\text { dummy variable }\end{array}$ & $0.41^{*}(1.83)$ & $\begin{array}{c}-0.22 * \\
(-1.73)\end{array}$ & $0.14(0.83)$ \\
\hline $\begin{array}{l}\text { Education year of } \\
\text { household }\end{array}$ & $0.45(0.45)$ & $\begin{array}{c}-0.02 * * \\
(-2.15)\end{array}$ & $-0.14(-0.19)$ \\
\hline Separability test & $\mathrm{F}=1.84$ & $\mathrm{~F}=7.74$ & $\mathrm{~F}=9.03$ \\
\hline Number of households & 123 & 232 & 154 \\
\hline
\end{tabular}

Note: Provincial dummy variables are included for regression.

*indicates significance at the $10 \%$ level of confidence.

** indicates significance at the $5 \%$ level of confidence.

$* * *$ indicates significance at the $1 \%$ level of confidence.
Table 4 shows that the negative effect of land size is only found in west regions, indicating that the more cultivated land is, the less demand for labor is. The possible reason for this result relies in the geographical characteristics of west region and its insufficiency of infrastructure. More specifically, even though west region has relatively wider land size, companies in east and costal area are reluctant to set up in west regions. In addition, family size is highly correlated with the labor demand. This result plays the significant role in the rejection of the null hypothesis of west and middle regions.

Besides, the number of children in each family has no significant influence on the labor demand, while in west region, the increase of children fraction would lead to less demand for labor demand. The economic reason for this is quite obvious since the giving birth to child will occupy working hours, which has negative effect on the total hours for farm activity.

Additionally, both the fraction of male and female have significantly negative effect on the labor demand in west region. In other words, the increase of the fraction of male and female in family member would have more influence in west region than in other two regions. This result is partly due to the insufficient development of infrastructure and technology, which force the agricultural production relying heavily on farm labor.

However, it should be noted that the fraction of male in west region does not affect the labor demand. Comparatively speaking, there are relatively more off-farm employed opportunities in east region. Compared with farm production, adult male prefer to work in enterprises. Except that, the relatively advanced technological level in farm production in ease region makes insignificant the output difference between male and female.

Another interesting result shown in Table 4 is that the average education year has negative influence on labor demand. The more education year is, the lower labor demand for agriculture is. The feature is consistent with the result obtained by Knight et al. (2011), showing that individuals with relatively more education years tend to migrant to east region especially coastal areas for better working opportunities resulting in the negative impact on farm production.

\section{Conclusion}

This paper used the CHIPS data for the analysis of separability of farm household between consumption and labor supply considerations in China. Our empirical results firstly show that the separation of agricultural household is closely related with economic level. Specifically, there exists the nonseparability of households in the west and middle regions of China. Only those households with medium land size in east China can reject the null hypothesis. Secondly, not only economic status of agricultural households but also less development of labor market in rural area leads to the nonseparability of agricultural households. 


\section{Acknowledgment}

The authors thank Sonoda Tadashi and Arayama Yuko for valuable comments and suggestions.

\section{References}

[1] Benjiamin, 1992. Household Composition, Labor Markets, and Labor Demand: Testing for Separation in Agricultural Household Models, Econometrical, Vol. 60, No. 2, pp.287-322.

[2] Audra J. Bowlus, Terry Sicular, 2003. Moving toward market? Labor allocation in rural China, Journal of Development Economics, Vol. 71, pp.561- 583 .
[3] Pranab Bardhan, Christopher Udry, 1999. Development Microeconomics, Oxford University Press.

[4] Micheael R. Carter and Y. Yao 2002. Local Versus Global Separability in Agricultural Household Models: The Factor Price Equalization Effect of Land Transfer Rights, American Journal of Agricultural Economics, Vol. 84, No. 3.pp.702-715.

[5] X.Wang, T. Herzfeld, T. Glauben, 2007. Labor allocation in transition: evidence from Chinese rural households, China Economic Review, Vol.18, pp.287-308.

[6] Knight, J., Deng. Q, Li, S., 2011. The puzzle of migrant labour shortage and rural labour surplus in China. China Economic Review, Vol. 22, pp. 585-600. 